TECHNICAL NOTE

L. Saba

G. Mallarini

\title{
Window Settings for the Study of Calcified Carotid Plaques with Multidetector CT Angiography
}

\begin{abstract}
SUMmARY: CT angiography (CTA) shows high sensitivity in detecting calcified plaques, but sometimes a bias in the exact quantification of stenosis degree occurs, mainly caused by the high linear attenuation coefficient of the calcified plaques. The purpose of this technical study was to evaluate the most appropriate CT window parameters for the assessment of calcified plaques stating which of them can provide the best inter-observer agreement. Scatter-plots and regression results showed the correlation between both width and level respectively depending on intraluminal Hounsfield units (HU) value (width $=$ intraluminal $\mathrm{HU} \times 2.07$; level $=$ intraluminal $\mathrm{HU} \times 0.72$ ). Obtained data indicated that the presence of different stenosis degrees did not modify visualization parameters.
\end{abstract}

A therosclerosis of extracranial carotid arteries is an important risk factor for cerebrovascular events. Every year in the United States, approximately 700,000 people experience a new or recurrent stroke. ${ }^{1}$ Carotid plaque is a complex structure made up of different components subject to a dynamic remodeling. ${ }^{2}$ Major or reduced stability of plaque varies in relation to the prevalence and different percentages of several components. ${ }^{2-7}$ According to predominant Hounsfield unit values, carotid plaques may be classified into 3 groups: soft plaques, fatty plaques, and calcified plaques. ${ }^{8-10}$ Each plaque type is characterized by specific features showing a different ischemic risk profile and a different imaging result. ${ }^{10-12}$ In particular, the study of calcified plaques is often difficult to perform with the available imaging techniques. With sonography, a calcified plaque produces an acoustic shadowing, ${ }^{13,14}$ which often does not allow a correct plaque assessment and the quantification of stenosis degree. ${ }^{15,16}$

CT angiography (CTA), on the other hand, shows a greater efficacy in the identification of calcified plaques. Yet a relevant bias in calcified plaque assessment is caused by the artifacts derived from its high linear attenuation level, which was indicated in previous studies on coronary plaque visualization. ${ }^{17,18}$ This has led many authors during the past years to consider the presence of calcified plaques as a serious limitation of CTA. ${ }^{19,20}$ Moreover, the presence of a plaque calcification may increase the risk of an overestimation of the plaque itself due to average volume artifacts. ${ }^{21}$ The recent advent of multidetector CT (MDCT) with an angiographic approach allows fast acquisitions of carotid vessels with submillimeter voxels, performed with the most highly developed machines, which are near-isotropic. ${ }^{22-24}$ The dataset obtained may be subsequently postprocessed with different techniques such as maximum intensity projection, multiplanar reconstruction, and volume rendering, ${ }^{25-29}$ which provide an improved diagnostic efficacy in

Received December 4, 2008; accepted December 13

From the Department of Science of the Images (L.S.), Policlinico Universitario, Cagliari, Italy; and Institute of Radiology of the University of Cagliari (G.M.), Cagliari, Italy.

Please address correspondence to Luca Saba, MD, Department of Science of the Images, Policlinico Universitario, s.s. 554 Monserrato (Cagliari) 09045, Italy; e-mail: lucasaba@ tiscali.it

Indicates article with supplemental on-line figures

DOI 10.3174/ajnr.A1509 the evaluation of calcified plaques. The aim of this study was to analyze CT features of calcified plaque and to determine which window parameters show the best agreement in the stenosis degree quantification of this plaque type.

\section{Materials and Methods}

\section{Demographic Data}

Two hundred eleven patients who had been studied in our department from January 2006 to December 2006 were retrospectively examined (163 men, 48 women; average age, 67 years; range, 31-85 years). Four hundred twenty-two carotid arteries were analyzed by using CTA, which was performed only when it had been ordered by the patient's physician as part of routine clinical care (using the same criteria as described in a previous work ${ }^{10}$ ). None of the patients who underwent CTA had contraindications to intravenous injection of iodinated contrast material. Because this study was retrospective and imaging was not additional to that performed routinely in this group of patients, it is the policy of our divisional research committee that specific ethics approval is not required. Part of the selected cohort $(n=104)$ had been former patients included in previous studies. ${ }^{30,31}$

\section{MDCTA Scanning Technique}

Angiographic CT was performed with a 4-detector-row spiral CT scanner (Mx8000; Philips [formerly Picker], Andover, Mass). Patients were placed in the supine position, with the head tilted back to prevent dental artifacts on the images. They were also instructed not to breathe or swallow. Arterial enhancement was provided by the intravenous administration of 100 - to $130-\mathrm{mL}$ nonionic iodinated contrast material (in 107 patients, Iomeron 350; Bracco, Milan, Italy; and in 104 patients, iopromide, Ultravist 370; Bayer HealthCare [formerly Schering], Leverkusen, Germany) at an injection speed of 4-6 $\mathrm{mL} / \mathrm{s}$ by using a power injector and an intravenous catheter inserted into the antecubital vein. We used a delay time variable from 11 to 18 seconds. Angiographic acquisition started at the C7 level and proceeded as far cephalic as possible, including the carotid siphon. CT technical parameters included the following: matrix, $512 \times 512$; FOV, $11-19 \mathrm{~cm} ; \mathrm{mAs}, 180-240 ; \mathrm{kV}, 120-140$.

\section{Phase I: Method of Evaluating Plaque Attenuation}

To identify calcified plaques to be included in our study, we measured Hounsfield units in the axial scans by using a similar method validated by Schroder et $\mathrm{al}^{8}$ to differentiate plaque configuration in the coronary arteries: 
- Fatty (soft) plaques: a plaque with attenuation values $<50 \mathrm{HU}$.

- Mixed (intermediate) plaque: a plaque with attenuation values between 50 and 119 HU.

- Calcified plaque: a plaque with attenuation $>120 \mathrm{HU}$.

For the measurement of Hounsfield unit attenuation, a circular or elliptical region-of-interest cursor was used in the predominant area of plaque, ${ }^{32}$ and those areas showing contamination induced by contrast material were carefully avoided. We used a region-of-interest area from 0.01 to $0.02 \mathrm{~cm}^{2}$. Identification of the plaque type was subsequently performed by 2 observers in consensus.

\section{Phase II: Window Level Evaluation in Axial Images}

In the retrospective study of images, window values were not previously planned, so each radiologist was free to use those window parameters that were judged most efficient to assess the stenosis degree in each patient. During all measurements, radiologists were asked to score intraluminal Hounsfield unit values. Thus, for each radiologist and for all calcified plaques, analyzed specific window width, window level, Hounsfield unit intraluminal measure, and corresponding stenosis degree were recorded. Finally, all data were correlated.

\section{Phase III: Method of Evaluating Stenosis Degree}

In the calcified plaques, carotid stenosis was measured and graded according to the North American Symptomatic Carotid Endarterectomy Trial (NASCET) criteria $^{33,34}$ : I, normal; II (1\%-29\%), mildly stenosed; III (30\%-49\%) and IV (50\%-69\%), moderately stenosed; V (70\%-99\%), severely stenosed; VI, occluded. The grade of stenosis was classified by 2 observers independently. Measurements to quantify stenosis degree were taken by selecting a plane perpendicular to the lumen center line as indicated by Ota et $\mathrm{al}^{35}$ by using a curved planar reconstruction algorithm. The value was calculated by comparing the stenosed segment diameter with the more distal normal one, in which stenosis was absent. Every time a near-occlusion condition $^{36,37}$ was detected, the above-described method was not applied; thus these patients were directly included in NASCET V group. In our final analysis, NASCET I (absence of plaque) and NASCET VI (complete occlusion) were excluded.

\section{Statistical Analysis}

The Cohen $\kappa$ statistic was applied to calculate agreement between observers in the categoric degree of stenosis: a weighted $\kappa$ was used because the categories were ordinal. Window parameters (width and level settings) of axial images were correlated with intraluminal Hounsfield unit values. Multiple scatterplots with their relative regression lines were elaborated a second time. All scatterplots resulted from joining all stenosis classes (NASCET II-V). Window parameters were then singularly recalculated for each class of stenosis to observe if the presence of a certain stenosis degree might determine any variations in window parameters. The Pearson correlation coefficient $(r)$ was calculated to assess the presence and strength of the association between intraluminal Hounsfield unit values, window width, and window level. Finally simple equations were obtained that would standardize studied parameters. Interobserver analysis for the assessed window level and width was provided by using Bland-Altman plots. $^{38} R$ software (www.r-project.org) was used for statistical analyses.

\begin{tabular}{|c|c|c|c|c|c|}
\hline \multicolumn{6}{|c|}{$\begin{array}{l}\text { Table 1: } \kappa \text { statistics for the comparison of stenosis grading } \\
\text { between observer } 1 \text { and observer } 2\end{array}$} \\
\hline \multirow{2}{*}{$\begin{array}{l}\text { NASCET } \\
\text { Class }\end{array}$} & \multicolumn{4}{|c|}{ Observer 2} & \multirow[b]{2}{*}{ Tota } \\
\hline & II & III & IV & V & \\
\hline \multicolumn{6}{|c|}{ Observer 1} \\
\hline II & 12 & 0 & 0 & 0 & 12 \\
\hline III & 1 & 28 & 1 & 1 & 31 \\
\hline IV & 0 & 2 & 28 & 3 & 33 \\
\hline V & 0 & 0 & 3 & 62 & 65 \\
\hline Total & 13 & 30 & 32 & 66 & 141 \\
\hline
\end{tabular}

Note:-NASCET indicates North American Symptomatic Carotid Endarterectomy Trial. * Measurements were made by selecting a plane perpendicular to the lumen center line.

\section{Results}

Four hundred twenty-two carotid arteries were studied, and 141 calcified plaques (average attenuation, $947 \mathrm{HU}$; range, 644.3-1137.7 HU) in 110 patients ( 82 men, 28 women; average age, 69 years; range age, 37-85 years), 126 fatty plaques (average attenuation, 41.3 HU; range, $24.4-48.9 \mathrm{HU}$ ), and 83 mixed plaques (average attenuation, $84.3 \mathrm{HU}$; range, 56.7115.1 HU) were detected.

In the 141 calcified plaques, observer 1 detected 12 NASCET II plaques, 31 NASCET III plaques, 33 NASCET IV plaques, and 65 NASCET V plaques, whereas observer 2 described 13 NASCET II plaques, 30 NASCET III plaques, 32 NASCET IV plaques, and 66 NASCET V plaques. From the obtained data, we derived an interobserver agreement of $92.2 \%$ with a $\kappa$ value of $0.885 \pm 0.033$ ( $95 \%$ confidence interval, 0.819-0.950), which indicated significant agreement (Table 1).

Given the total amount/sum of measurements (141 from observer 1 plus 141 from observer 2), scatterplots confirmed the correlation between window level and width (Fig 1A) and the relationship between intraluminal value and window level (Fig $1 B$ ) and between intraluminal value and window width respectively (Fig 1C). All these parameters showed a significant statistical correlation.

The Pearson correlation coefficient was $0.891(P<.01)$ between window level and window width values; $r$ was 0.743 $(P<.01)$ between intraluminal Hounsfield unit value and window level; $r$ was $0.808(P<.01)$ between intraluminal Hounsfield unit value and window width (Table 2). In particular, the symmetry of scatterplot 1 (Fig 1A) was evident $(r=$ $0.891)$.

Thus, from the regression function of scatterplot 1 , we can infer the following equation: Width $=2.81 \times$ Level (first width equation), which postulated that the width should be 2.81 times the level. Scatterplot 2 regression line (Fig $1 B$ ) derived the following equation: Level $=0.72 \times$ Intraluminal $\mathrm{HU}$ (level equation), which suggested that the level should be 0.72 times the Hounsfield unit intraluminal value. Finally, by the analysis of the regression line of scatterplot 3 (Fig 1C), we derived this equation: Width $=2.07 \times$ Intraluminal $\mathrm{HU}(\mathrm{sec}-$ ond width equation), which demonstrated that the width should be 2.07 times the Hounsfield unit intraluminal value.

The relationships between window level and width, intraluminal value and window level, and intraluminal value and window width were respectively analyzed according to stenosis degree, ranging from NASCET II to NASCET V. This further analysis was performed as a double check to evaluate 

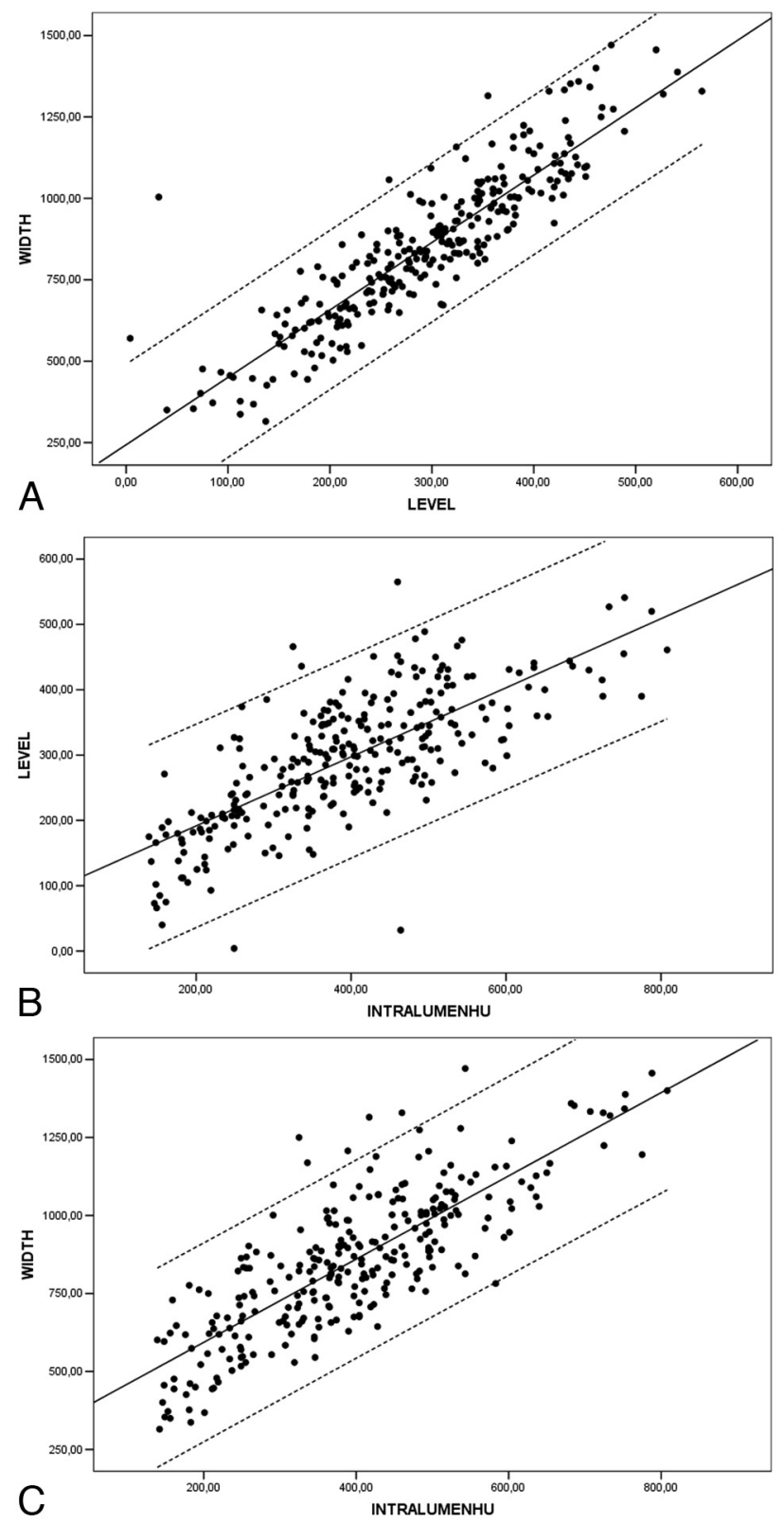

Fig 1. $A$, Scatterplot between width and level (NASCET II-V) with linear regression through the origin, with a $99 \%$ mean predictive interval and $99 \%$ individual predictive interval. Width $=2.81 \times$ Level. $B$, Scatterplot between intraluminal Hounsfield unit values (IntraluminHU) and level (NASCET II-V) with linear regression through the origin with a $99 \%$ mean predictive interval and a $99 \%$ individual predictive interval. Level $=0.72 \times$ Intraluminal HU. C, Scatterplot between intraluminal Hounsfield unit value and width (NASCET II-V) with linear regression through the origin with a 99\% mean predictive interval and $99 \%$ individual predictive interval. Width $=2.07 \times$ Intraluminal HU Value.

the eventual interference of stenosis degree with visualization parameters. We could observe that there were no significant differences between the various stenosis degrees. All these data, grouped according to stenosis classes, constantly indicated, through the Pearson correlation, a significant statistical value, which showed a strong association among the 3 studied parameters: width-level, intraluminal Hounsfield unit-level, and intraluminal Hounsfield unit-width (Table 2). Intraobserver agreement calculated by using Bland-Altman plots demonstrated a good concordance in the window width analysis but a suboptimal concordance in the window level analysis (Fig 2).

\section{Discussion}

The purpose of this study was to evaluate the CT window parameters in the study of calcified plaques, defining which of them provides the best interobserver agreement to obtain an optimal reproducibility.

The assessment of the calcified plaque is important because even if calcification is not typical for the unstable plaque, ${ }^{39}$ its accurate depiction allows planning of the arteriotomy site or extent of endarterectomy ${ }^{40}$ and predicting the hardness of plaque in carotid angioplasty and stent placement. ${ }^{41}$ Moreover a correct stenosis degree evaluation influences the decision to intervene, by using surgical or endovascular techniques, because it is primarily based on the percentage of luminal narrowing of the vessel.

Measurement of stenosis degree in calcified plaques requires some peculiar assessment procedures, taking advantage of all most frequently used imaging techniques such as sonography, MR, digital subtraction angiography (DSA), and CTA. In a sonographic echo-color doppler examination, the presence of a calcified component in the plaque determines the presence of an acoustic shadowing, which may keep radiologists from correctly visualizing the carotid structures. ${ }^{13,14}$ For this reason, it frequently happens that patients who previously underwent a sonographic examination need to undergo a second-level examination (CTA-MR imaging) because the operator could not measure stenosis degree due to the presence of acoustic shadowing.

MR imaging easily depicts calcified structures, but specific sequences must be used. ${ }^{42-44}$ Calcification, in fact, was not discernible from the lumen on black-blood images but is distinguishable from the bright lumen on time-of-flight angiograms. Puppini et $\mathrm{al}^{45}$ demonstrated that MR imaging sensitivity in the detection of calcifications is $80 \%$. As reported by Kopps et $\mathrm{al}^{46}$ during the study of calcified plaques of the aorta and of femoral arteries, MR imaging sometimes showed signal intensity loss typical of the presence of calcifications, though after histologic examination, no calcified plaques were found (false-positive presence). Link et $\mathrm{al}^{47}$ demonstrated that the presence of calcified plaques was correctly interpreted with DSA in only $56 \%$ of patients. Moreover, DSA was associated with a significant periprocedural morbidity risk of $0.5 \%-4 \%$.

CTA has a high sensitivity in detecting calcified structures; sometimes a bias in the exact evaluation of stenosis degree may be caused by the high linear attenuation coefficient of the calcified plaques. ${ }^{48}$ Without a correct setup, visualization parameters may significantly alter the resulting image. Moreover, peripheral calcification of the arterial wall causes artifacts that interfere with the evaluation of the stenosis degree.

The most efficient window and level settings for the display of carotid stenosis with mural calcifications are still unknown. ${ }^{49}$ In a previous study, ${ }^{31}$ we demonstrated that the type (fatty, mixed, or calcified) of plaque affected the interobserver agreement in the carotid artery stenosis degree quantification and that, in particular, carotid arteries with calcified plaque had lower $\kappa$ values if compared with mixed or fatty ones. The use of wrong width/level parameters can result in a low interobserver agreement. The best value with a fixed width/level for the stenosis quantification of calcified carotid plaque was 0.668 . In that work, ${ }^{31}$ we studied window parameters to identify the best method to achieve high reproducibility (interob- 
Table 2: Pearson correlation calculation between window level, window width, and intraluminal Hounsfield unit values in NASCET classes*

\begin{tabular}{lccccc}
\hline Pearson Correlation Variables & NASCET II-V $(r)$ & NASCET II $(r)$ & NASCET III $(r)$ & NASCET IV $(r)$ & NASCET V $(r)$ \\
\hline Window level-window width & 0.891 & 0.928 & 0.890 & 0.905 & 0.881 \\
IntraluminHU value-window level & 0.743 & 0.753 & 0.718 & 0.689 & 0.763 \\
IntraluminHU value-window width & 0.808 & 0.724 & 0.738 & 0.786 & 0.836 \\
\hline
\end{tabular}

Note:- IntraluminHU indicates intraluminal Hounsfield unit.

* Correlation is significant at the 0.01 level (2-tailed).
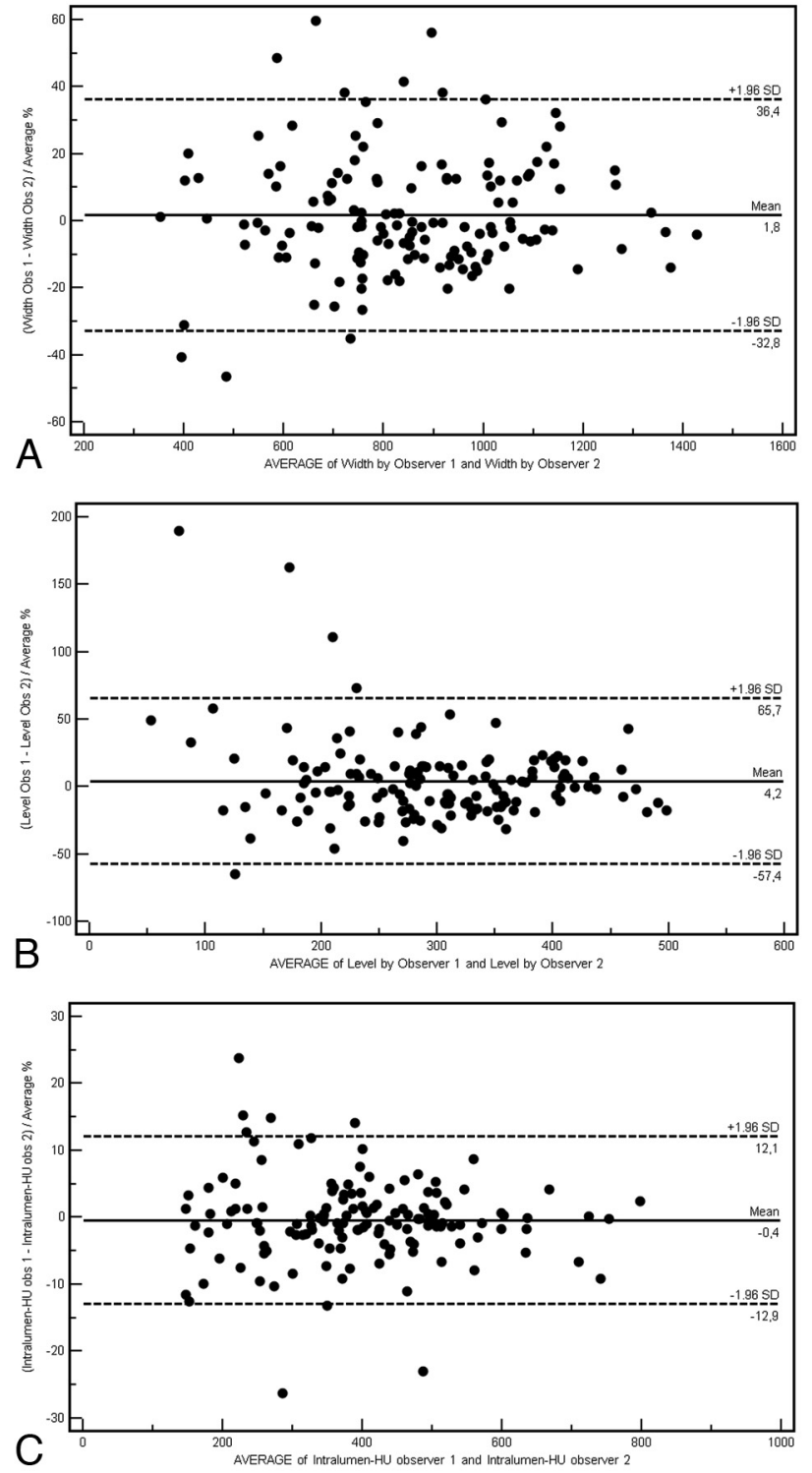

Fig 2. Bland-Altman plots of intraobserver variability in the window width $(A)$, window level $(B)$, and intraluminal Hounsfield unit measurements (C). Obs indicates observer. Intralumin-HU indicates intraluminal Hounsfield unit.

server agreement) in the quantification of calcified carotid artery stenosis degree.

In the analysis of carotid vessels, it is important to keep in mind that 2 of the most recurrent artifacts connected with endoluminal contrast injection are the so called "halo" and "edge blur." 50 "Edge blur" refers to the transition or sharpness of the outer luminal margin as a percentage of the luminal diameter. "Halo" artifacts refer to periluminal increased attenuation (partially saturated pixels). ${ }^{50}$ Actually, the tendency is to use speed flows ( $\geq 3 \mathrm{~mL} / \mathrm{s})$ to obtain a major intraluminal opacification and, therefore, a better postprocessing visualization. Moreover, a high intraluminal Hounsfield unit value allows a clear evaluation of luminal shape by producing a highcontrast interface between the contrast medium and the vascular wall. For our study, we applied this approach, obtaining an average intraluminal opacification of $392 \pm 138 \mathrm{HU}$ (minimum, $139 \mathrm{HU}$; maximum, $808 \mathrm{HU}$ ). In 1997, Claves et $\mathrm{al}^{50}$ reported, in phantoms, intraluminal values that ranged between 150 and $200 \mathrm{HU}$ as optimal values for a correct evaluation of stenosis degree. Nevertheless high Hounsfield unit values lower the edge blur artifacts, whereas halo artifacts do not appear to be connected with intraluminal values. The degree of halo artifacts does not increase with higher attenuation values.

The first scores we evaluated were window width and level. Frequently, studies report fixed values or value range ${ }^{31,38}$ presets. On the basis of our experience, ${ }^{31}$ we guess that this approach provides good visualization results in the study of mixed and fatty plaques, whereas it is suboptimal in the evaluation of calcified plaques (Fig 3). By the analysis of the obtained data and of the scatterplots, we can state that actually a fixed window value to be applied does not exist because width and window level results are strictly dependent on intraluminal Hounsfield unit values. With the progressive increase of this value (with a different slope), width and window level increase as well. We also derived from these data some equations that explain the tendency of window parameters in relation to the intraluminal Hounsfield unit. Optimal window parameters may be easily obtained by just measuring intraluminal Hounsfield unit values and subsequently applying the second width equation with the first level equation:

Width $=$ Intraluminal $\mathrm{HU} \times 2.07$,

Level $=$ Intraluminal $\mathrm{HU} \times 0.72$.

As a further step, we evaluated whether any differences existed in relation to different stenosis degrees, but the obtained results showed that from NASCET II up to NASCET V, no significant statistical difference resulted relative to this point.

The 2 observers measured the same window width, window level, and intraluminal Hounsfield unit independently from each other, and interobserver agreement was assessed by using Bland-Altman plots to visualize clearly the differences between the 2 observers. The analysis of Bland-Altman plots demonstrated good concordance (Fig 2) in the window width but a suboptimal concordance in the window level analysis. The concordance in the measurement of Hounsfield unit values was extremely high.

Our study has some limitations. First, this is a retrospective study. Second, the resolution of 3D CTA depends on the orientation of the vessel because the pixels are anisotropic. The resolution is approximately $0.2-0.3 \mathrm{~mm}$ in the transverse plane but only $0.7 \mathrm{~mm}$ in the $\mathrm{z}$-axis; this may limit the mea- 


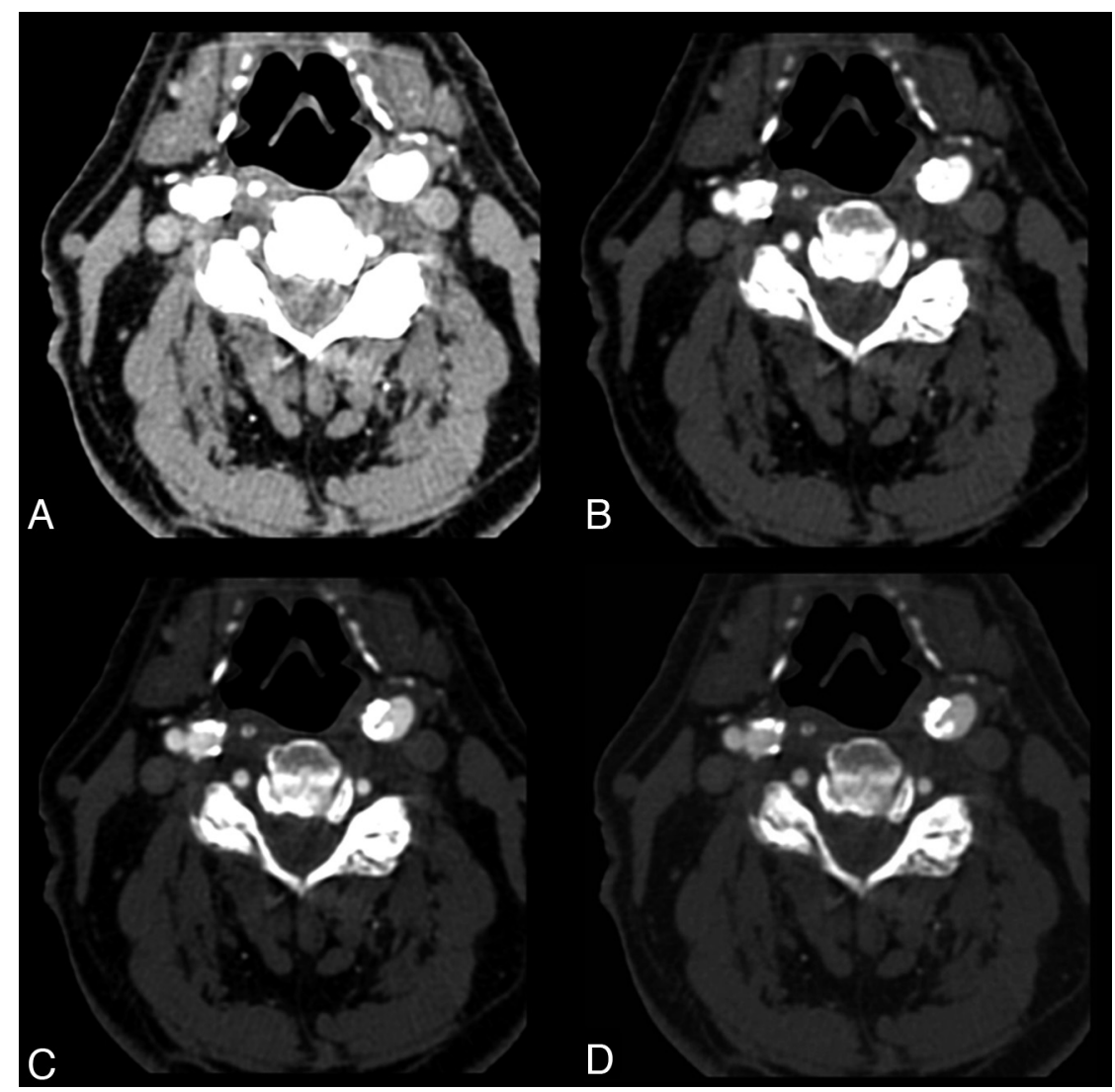

Fig 3. A 68-year-old man. CT axial images applying different window parameters. $A$ and $B$, Intraluminal Hounsfield unit value is 547 (right bulbus). With a 275 width and 30 level ( $A$ ) and $600 / 200(B)$, it is not possible to differentiate lumen from calcification. $C$, With $800 / 300$, it is possible to differentiate opacified lumen and calcification. $D$, By using equations described in this article, we obtained window parameters of 1132/394; a clear differentiation between lumen and parietal calcifications is visible.

surement of internal carotid artery stenosis (in particular in the NASCET V class).

\section{Conclusions}

Our study results show that the application of optimized window and level settings at CTA is strictly dependent on Hounsfield unit intraluminal values and that these levels are not necessarily correlated with stenosis degree.

\section{References}

1. Thom T, Haase N, Rosamond W, et al. Heart disease and statistics: 2006 update-a report from the America Heart Association Statistics Committee and Stroke Statistics Subcommitee. Circulation 2006;113:e85-151. Epub 2006 Jan 11

2. Hardie $\mathrm{AD}$, Cramer $\mathrm{CM}$, Raghavan $\mathrm{P}$, et al. The impact of expansive arterial remodeling on clinical presentation in carotid artery disease: a multidetector CT angiography study. AJNR Am J Neuroradiol 2007;28:1067-70

3. Virmani R, Ladich ER, Burke AP, et al. Histopathology of carotid atherosclerotic disease. Neurosurgery 2006;59:S219-27

4. Ouhlous M, Flach HZ, de Weert TT, et al. Carotid plaque composition and cerebral infarction: MR imaging study. AJNR Am J Neuroradiol 2005;26:1044-49

5. Li ZY, Howarth SP, Tang T. Structural analysis and magnetic resonance imaging predict plaque vulnerability: a study comparing symptomatic and asymptomatic individuals. J Vasc Surg 2007;45:768-75

6. Devuyst G, Piechosky-Jozwiak B, Bogousslavsky J. Arterial wall imaging. Front Neurol Neurosci 2006;21:19-26

7. Nandalur KR, Baskurt E, Hagspiel KD. Calcified carotid atherosclerotic plaque is associated less with ischemic symptoms than is noncalcified plaque on MDCT. AJR Am J Roentgenol 2005;184:295-98

8. Schroeder S, Kopp AF, Baumbach A, et al. Noninvasive detection and evaluation of the atherosclerotic plaque with multislice computed tomography. J Am Coll Cardiol 2001;37:1430-35

9. de Weert TT, Ouhlous M, Meijering E, et al. In vivo characterization and quan- tification of atherosclerotic carotid plaque components with multidetector computed tomography and histopathological correlation. Arterioscler Thromb Vasc Biol 2006;26:2366-72

10. Saba L, Caddeo G, Sanfilippo R, et al. Efficacy and sensitivity of axial scans and different reconstruction methods in the study of the ulcerated carotid plaque by using multi-detector-row $\mathrm{CT}$ angiography: comparison with surgical results. AJNR Am J Neuroradiol 2007;28:716-23

11. Virmani R, Kolodgie FD, Burke AP, et al. Lessons from sudden coronary death a comprehensive morphological classification scheme for atherosclerotic lesions. Arterioscler Thromb Vasc Biol 2000;20:1262-75

12. Newby AC, Libby P, van der Wal AC. Plaque instability: the real challenge for atherosclerosis research in the next decade? Cardiovasc Res 1999;41:321-22

13. Chong WK, Lawrence R, Gardner J, et al. The appearance of normal and abnormal arterial morphology on intravascular ultrasound. Clin Radiol 1993;48:301-06

14. Wolverson MK, Bashiti HM, Peterson GJ. Ultrasonic tissue characterization of atheromatous plaques using a high resolution real time scanner. Ultrasound Med Biol 1983;9:599-609

15. Erickson SJ, Mewissen MW, Foley WD, et al. Stenosis of the internal carotid artery: assessment using color Doppler imaging compared with angiography. AJR Am J Roentgenol 1989;152:1299-305

16. Steinke W, Meairs S, Ries S, et al. Sonographic assessment of carotid artery stenosis: comparison of power Doppler imaging and color Doppler flow imaging. Stroke 1996;27:91-94

17. Grosse C, Globits S, Hergan K. Forty slice spiral computed tomography of the coronary arteries: assessment of image quality and diagnostic accuracy in a non-selected patient population. Acta Radiol 2007;48:36-44

18. Chartrand-Lefebvre C, Cadrin-Chenevert A, Bordeleau E, et al. Coronary computed tomography angiography: overview of technical aspects, current concepts, and perspectives. Can Assoc Radiol J 2007;58:92-108

19. Cumming MJ, Morrow IA. Carotid artery stenosis: a prospective comparison of CT angiography and conventional angiography. AJR Am J Roentgenol 1994; 163:517-23

20. Schwartz RB, Jones KM, Chernoff DM, et al. Common carotid artery bifurcation: evaluation with spiral CT. Radiology 1992;185:513-19

21. Prokop M, Shin OS, Schanz A, et al. Use of maximum intensity projection in CT angiography. Radiographics 1997;17:433-51 
22. Napoli A, Fleischmann D, Chan FP, et al. Computed tomography angiography: state of the art imaging using multi-detector row technology. J Comput Assist Tomogr 2004;28:S32-45

23. Prokop M. General principles of MDCT. Eur J Radiol 2003;45:S4-10

24. Fleischmann D, Hallet RL, Rubin GD. CT angiography of peripheral arterial disease. J Vasc Interv Radiol 2006;17:3-26

25. Magnusson M, Lenz R, Danielson PE. Evaluation of methods for shaded surface display of CT volumes. Comput Med Imaging Graph 1991;15:247-56

26. Dalrymple NC, Prasad SR, Freckleton MW, et al. Introduction to the language of three-dimensional imaging with multi-detector CT. Radiographics 2005;25:1409-28

27. Calhoun PS, Kuszyk BS, Heath DG, et al. Three-dimensional volume rendering of spiral CT data: theory and method. Radiographics 1999;19:745-64

28. Luccichenti G, Cademartiri F, Pezzella FR, et al. 3D reconstruction techniques made easy: knowhow and pictures. Eur Radiol 2005;15:2146-56

29. Lell MM, Anders K, Uder M, et al. New techniques in CT angiography. Radiographics 2006;26(suppl 1):S45-S62

30. Saba L, Sanfilippo R, Pascalis L, et al. Carotid artery wall thickness and ischemic symptoms evaluation using multi-detector-row CT angiography. Eur Radiol 2008;18:1962-71. Epub 2008 Apr 11

31. Saba L, Mallarini G. MDCTA in the study of carotid plaque stenosis degree: evaluation of inter-observer agreement. AJR Am J Roentgenol 2008;190:W41-46

32. Kullo IJ, Edwards WD, Schwartz RS. Vulnerable plaque: pathobiology and clinical implications. Ann Intern Med 1998;129:1050-60

33. Beneficial effect of carotid endarterectomy in symptomatic patients with high grade stenosis: North American Symptomatic Carotid Endarterectomy Trial Collaborators. N Engl J Med 1991;325:445-53

34. Barnett HJ, Taylor DW, Eliasziw M, et al. Benefit of carotid endarterectomy in patients with symptomatic moderate or severe stenosis: North American Symptomatic Carotid Endarterectomy Trial Collaborators. N Engl J Med 1998;339:1415-25

35. Ota H, Takase K, Rikimaru H, et al. Quantitative vascular measurements in arterial occlusive disease. Radiographics 2005;25:1141-58

36. El-Saden SM, Grant EG, Hathout GM, et al. Imaging of the internal carotid artery: the dilemma of total versus near total occlusion. Radiology 2001;221:301-08

37. Bartlett ES, Walters TD, Symons SP, et al. Diagnosing carotid stenosis near occlusion by using CT angiography. AJNR Am J Neuroradiol 2006;27:632-37

38. Fleiss JL, ed. Statistical Methods for Rates and Proportions. 2nd ed. New York: Wiley; 1981:212
39. Nandalur KR, Hardie AD, Raghavan P, et al. Composition of the stable carotid plaque: insights from a multidetector computed tomography study of plaque volume. Stroke 2007;38:935-40

40. Oliver TB, Lammie GA, Wright AR, et al. Atherosclerotic plaque at the carotid bifurcation: CT angiographic appearance with histopathologic correlation. AJNR Am J Neuroradiol 1999;20:897-901

41. Niwa Y, Katano H, Yamada K. Calcification in carotid atheromatous plaque: delineation by 3D-CT angiography, compared with pathological findings. Neurol Res 2004;26:778-84

42. Saam T, Cai J, Ma L, et al. Comparison of symptomatic and asymptomatic atherosclerotic carotid plaque features in vivo MR imaging. Radiology 2006;240:464-72

43. Cappendijk VC, Cleutjens KBJM, Kessels AG, et al. Assessment of human atherosclerotic carotid plaque components with mutlisequence MR imaging: initial experience. Radiology 2005;234:487-92

44. Yuan C, Mitsumori LM, Ferguson MS, et al. In vivo accuracy of multispectral magnetic resonance imaging for identifying lipid-rich necrotic cores and intraplaque hemorrhage in advanced human carotid plaques. Circulation 2001;104:2051-56

45. Puppini G, Furlan F, Cirota N, et al. Characterization of carotid atherosclerotic plaque: comparison between magnetic resonance imaging and histology. $R a-$ diol Med 2006;111:921-30

46. Kopps A, Ittrich H, Petri S. Multicontrast-weighted magnetic resonance imaging of atherosclerotic plaques at 3.0 and $1.5 \mathrm{~T}$ : ex vivo comparison with histopathologic correlation. Eur Radiol 2007;17:279-86

47. Link J, Brossmann J, Grabener M, et al. Spiral CT angiography and selective digital subtraction angiography on internal carotid artery stenosis. AJNR Am J Neuroradiol 1996;17:89-94

48. Alvarez-Linera J, Benito-Leon J, Escribagno J, et al. Prospective evaluation of carotid artery stenosis: elliptic centric contrast-enhanced MR angiography and spiral CT angiography compared with digital subtraction angiography. AJNR Am J Neuroradiol 2003;24:1012-19

49. Berg M, Zhang Z, Ikonen A, et al. Multi-detector row CT angiography in the assessment of carotid artery disease in symptomatic patients: comparison with rotational angiography and digital subtraction angiography. AJNR Am J Neuroradiol 2005;26:1022-34

50. Claves JL, Wise SW, Hopper KD, et al. Evaluation of contrast densities in the diagnosis of carotid stenosis by CT angiography. AJR Am J Roentgenol 1997; 169:569-73 